\title{
O PRESENTE ESQUECIDO ENTRE O SAUDOSISMO E O UTOPISMO: NOTAS PARA PENSAR A EDUCAÇÃO
}

\author{
THE FORGOTTEN PRESENT BETWEEN NOSTALGIA AND THE UTOPIANISM: NOTES TO \\ THINK EDUCATION
}

\author{
CLAUDIONEI VICENTE CASSOL ${ }^{1 ; *}$ \\ ORCID: https://orcid.org/0000-0001-7837-887X \\ SIDINEI PITHAN DA SILVA $2 ; * *$ \\ ORCID: https://orcid.org/0000-0001-6400-4631
}

BAUMAN, Zygmunt. Retrotopia. Rio de Janeiro: Zahar, 2017.

Esta resenha tem o objetivo de apresentar a recente obra de Zygmunt Bauman - Retrotopia (2017) -, destacando e analisando alguns pontos de sua crítica à sociedade contemporânea, bem como buscando algumas aproximações para pensar a educação. Esta obra de Bauman não se mantém somente na descrição superficial de nossa condição social, tampouco apenas explicita e explica as dimensões profundas da crise de nosso tempo, mas sugere uma via que vale também para os envolvidos na educação: a cultura do diálogo. Os temas do neoconservadorismo, presentes na condição acelerada da modernização, constituem um sentimento e um caldo cultural produzidos pelos novos administradores da ordem, os quais ditam e criam o molde para as novas formas de vida (pautadas no fundamentalismo, no consumismo e no individualismo), o que desafia os educadores e os agentes sociais, intelectuais e políticos a compreender e a intervir. De outra parte, a educação, especialmente a formal - de sala de aula, de escola -, não resolve sozinha e tampouco define o futuro da humanidade, dos indivíduos e do cosmos, mas, sem ela, como escreve Paulo Freire (1996), as possibilidades se reduzem e as relações são comprometidas.

A prolífera obra do filósofo social Zygmunt Bauman (1925-2017) surpreende pela capacidade intelectual de debater temáticas que, no cotidiano apressado da existência superficial, conduzido pelos apelos consumistas, passam ao largo da crítica individual e coletiva. Enfrentar a problemática apresentada na sociologia pluralizadora de Bauman é pôr-se de modo crítico e hermenêutico diante das situações diversas que a condição humana incorpora, por sua natureza, e desenvolve a partir das compreensões e ações dos indivíduos. Retrotopia (2017) desenha uma problematização profunda para mostrar que é da condição humana a formação e, desse modo, a força da cultura e as heranças históricas e sociais são primordiais porque parecem ditar os direcionamentos a que as existências individuais estão submetidas. Antes, porém, de caracterizarmos os aspectos centrais da obra, voltemos nossa atenção ao lugar de reconhecimento de Bauman junto à intelectualidade contemporânea, e mesmo

\footnotetext{
${ }^{1}$ Universidade Regional Integrada do Alto Uruguai e das Missões. Frederico Westphalen, RS, Brasil.

* Professor na Universidade Regional Integrada do Alto Uruguai e das Missões (URI). Frederico Westphalen, RS e CEEDO. Cerro Grande, RS, Brasil. < cassol@uri.edu.br>.

2 Universidade Regional Integrada do Noroeste do Estado do Rio Grande do Sul (Unijuí). Ijuí, RS, Brasil.

** Professor do Departamento de Humanidades e Educação da Universidade Regional Integrada do Noroeste do Estado do Rio Grande do Sul (Unijuî). Professor do Curso de Educação Física e do Programa de Pós-Graduação em Educação nas Ciências da Unijuí. Ijuí, RS, Brasil. <sidinei.pithan@unijui.edu.br>.
} 
sobre sua preocupação com o tema da utopia em obras anteriores, o que pode facilitar nossa compreensão do significado da obra Retrotopia para pensar a sociedade e a educação.

Distintos e reconhecidos intelectuais, como Gianni Vattimo (2017), Umberto Eco (2017) e Agnes Heller e Ferenc Fehér (1994), têm percebido, no conjunto das obras de Zygmunt Bauman, uma forma potente para pensar e compreender a sociedade contemporânea. Umberto Eco (2017), por exemplo, sugere que o termo modernidade líquida ou sociedade líquida deva-se a Bauman. $\mathrm{O}$ autor considera que este termo tenha tido seu nascedouro na concepção pós-modernista, a qual emergiu no final do século XX, quando declarou a crise das "grandes narrativas" da modernidade. Heller e Fehér (1994, p. 37), possivelmente movidos pela compreensão de Foucault acerca das relações entre "os intelectuais e o poder" (FOUCAULT, 2001, p. 70), entendem que Bauman permite pensar a intelectualidade hoje não como uma espécie de vanguarda, que profetiza ou legisla sobre o mundo, mas, quem sabe, o interpreta e o traduz.

Vattimo (2017), embora tecendo muitos elogios a Bauman, confessa que nunca entendeu bem se o autor era favorável às concepções pós-modernas (desconstrucionistas) ou contrário a elas, e acredita, até mesmo, que ele (Bauman) nunca avaliou bem isso. Bauman (1998, 2011), todavia, quando acusado de pós-modernista, tentou se justificar, sugerindo que somente com a ideia de iconoclastia, ou mesmo de desconstrução, poderemos refletir sobre o nosso passado e construir, no presente, pela via da política e da educação, uma perspectiva para o futuro. "As utopias iconoclastas", segundo ele, "não se conduzem por meio de desenhos ou conselhos, mas sim por meio da reflexão crítica sobre práticas e crenças existentes" (BAUMAN, 2009a, p. 18). Eis um lugar fundamental e importante da educação na configuração de outro mundo possível em tempos líquidos: radicalizar as possibilidades democráticas, como afirmou Bauman em diálogo com a escrita de Giroux e Rorty (BAUMAN, 2009b).

Para Bauman, assim como para Russel Jacoby $(2001,2007)$, as utopias ainda possíveis não podem ser mais pensadas a partir de uma ciência fundada em certezas, ou mesmo em cálculos matemáticos, que permitiriam uma engenharia do social rumo a um mundo ordenado, que tem um telos de perfeição definitivo ao final (uma linha de chegada). "O horizonte que a modernidade mirava era a visão de uma sociedade estável, solidamente enraizada [...]”, escreveu Bauman em Legisladores e intérpretes: sobre modernidade, pós-modernidade e intelectuais (2010, p. 12). Esse tipo de utopia merece ser criticada, evidenciando-se seus riscos, horrores e perigos ao longo do século XX com o fenômeno das guerras e do totalitarismo. Talvez possamos acolher a obra Retrotopia (2017) como uma espécie de crítica a um retorno de utopias conservadoras e conformistas que não miram o futuro como alvo a ser desejado, o que já fora criticado por Bauman em sua crítica da modernidade, mas que miram e tentam tornar desejável um mundo estável e isento de contradições que estaria no passado, na era pré-moderna, anteriores a Hobbes ou mesmo ao nascimento do Estado-nação.

A retrotopia, tema central da análise de Bauman (2017), é uma espécie de leitura de nossa condição social contemporânea: a perda de confiança no progresso foi substituída pela aposta imaginária e saudosista em um passado ideal. O sentimento de que poderíamos construir um lugar melhor no futuro, tal como apostaram as utopias modernas, foi substituído por uma visão saudosista e nostálgica de que há uma comunidade ideal no passado. Bauman (2017) tematiza a questão do cenário contemporâneo de violência, solidão, desemprego e exclusão social. Trata das novas condições vividas pela sociedade, cada vez mais envolta num tipo de violência que é produzida e animada por um sentimento difuso de ódio, disseminado por aqueles que têm interesse no poder. Talvez aqui ele até avance em relação à reflexão feita por Russel Jacoby (2001) na obra O fim da utopia: política e cultura na era da apatia, uma vez que parece mostrar não somente o fim da utopia e a cultura da apatia, como previa o autor, mas, fundamentalmente, o surgimento da retrotopia.

Retrotopia (2017) enfrenta a problemática da “"violência autotélica', ou seja, aquela que é seu próprio motivo e propósito; uma violência sem sentido e, pior: ela tende a ser despropositada, dolorosa e desonrosa para o seu próprio perpetrador" (BAUMAN, 2017, p. 40-41). A obra denuncia a ação negativa de uma educação também autotélica, oposta à solidariedade: "Estão nos ensinando a autossuficiência [...] não contar com ninguém, exceto conosco" (BAUMAN, 2017, p. 47), ressuscitando a condição humana pré-hobbesiana do homo homini lupus, do estado de guerra de todos contra todos. A sombra do passado atinge os tempos presentes e implica compreensões e ações dos indivíduos no perigo da supressão da liberdade. O maior bem e ideal do ser humano (BAUMAN, 2017, p. 120) aproxima-se 
sorrateiro quando da conexão saudosista e apressada, por vezes fortemente comercializada, com um distante tempo de soluções mágicas. A farsa da história torna-se palpável e revitaliza-se via império fake, que desautoriza as construções científicas, desqualifica a ação educativa, inviabiliza diálogos e tende a eliminar o diferente e a diferença.

$\mathrm{O}$ autor estrutura a obra em seis partes. $\mathrm{Na}$ introdução, nomina e explicita o espírito de nostalgia de nosso tempo. No capítulo 1 , De volta a Hobbes, tematiza a ideia de retrotopia, fazendo um retorno à filosofia de Hobbes, evidenciando como o neoliberalismo operante no adentrar do século XXI cria um sentimento de competição, violência, medo e ódio, em que parece que somos todos inimigos e estamos em uma luta selvagem, retrato típico de uma sociedade individualizada. No capítulo 2 , com o título De volta às tribos, o autor mostra os fechamentos e os muros culturais criados pelas políticas atuais do Estado-nação, a fim de definir claramente o nós e o eles, gerando uma condição na qual uns se consideram superiores e declaram os outros inferiores, a fim de deixar as coisas como estão, ampliando as políticas de ódio aos excluídos e abandonados, o que interessa ao poder dominante. Também aborda a problemática da perda da fé e da aposta da política em modelar o futuro, com a ideia difusa e manipulatória que estabelece a crença de que nós não somos aqueles que controlam o presente.

No capítulo 3, De volta à desigualdade, Bauman compara as formas de política assumidas pelo Estado de bem-estar social, nos gloriosos 30 anos do pós-guerra, com as políticas neoliberais da atualidade em relação ao comportamento acerca da desigualdade, condição fundamental para entender o fenômeno da retrotopia. Estão em questão as novas relações emergentes entre capital-trabalho mediadas pelas políticas de Estado no cenário da globalização; leitura que interessa sobremaneira à educação, uma vez que permite entender a fragilização do sentido público e democrático envolto na tarefa educacional. No capítulo 4, De volta ao útero, trata da desintegração dos laços humanos e da privatização da esperança no cenário da modernidade líquida, o que tem significado uma mudança mais ampla da cultura de responsabilidades da sociedade com a vida dos indivíduos. O eu se torna o único lugar difundido pelos administradores da ordem como lugar confiável. O lugar de compromisso social pela melhoria de vida dos trabalhadores foi transferido para a agência individual. Dá a impressão de não haver interesse comum para construir pautas emancipatórias, pois todos parecem estar "numa guerra de todos contra todos" (BAUMAN, 2017, p. 114).

Ambos os fenômenos, "de volta às tribos" e "de volta ao útero", aparentam ser tributários do "de volta a Hobbes", e "se originam em grande parte na mesma fonte: o medo do futuro embutido no presente exasperantemente caprichoso e incerto" (BAUMAN, 2017, p. 141). No epílogo da obra, Bauman evidencia a dificuldade de enfrentar a situação, mas discorda da ideia de que não há alternativa, traduzindo sua dose de esperança e aposta para o futuro: "estamos numa situação ou/ou: estamos diante da perspectiva de nos darmos as mãos ou de rumar para as nossas valas comuns" (2017, p. 155).

O pano de fundo escolhido por Bauman na obra Retrotopia (2017) parece ser o do deslocamento do lugar do Estado-nação em um cenário de sociedade globalizada, conjuntamente com a emergência de novas mentalidades e sentimentos. No auge da modernidade sólida, leia-se no decorrer do século XX, o Estado assumira uma função de produzir a segurança ou mesmo de universalizar o direito. No cenário da modernidade líquida, ao final do século XX, a ideia clássica de Estado-nação assume funções ligadas a uma maior ampliação das liberdades econômicas, mas sem as preocupações sociais com a vida dos indivíduos. O termo globalização significa mais o que o mundo está fazendo de nós, das culturas, das nações, dos indivíduos e dos povos, do que aquilo que podemos fazer com ele. Ele representa a forma como o poder tornou-se global e se separou da política, que continua local (BAUMAN, 1999).

Isso representa uma perda no sentido da força do Estado-nação em relação ao controle e à produção de saídas para os problemas cada vez mais globais. Também representa uma descrença dos indivíduos com o futuro dos marcos civilizacionais postos e concentrados na ideia de política, de cultura, de educação, de progresso e de democracia. Retrotopia, nesse sentido, é um conceito novo cunhado por Bauman para expressar as contradições de nosso tempo. Com ele, Bauman parece expor a realidade do presente e as condições dos indivíduos diante dela: reconhecimento da situação, mas impotência, descaso, desobrigação em mover-se para ações de alguma mudança, transformação, compromisso com a continuidade da vida e com as operações constantes de aprimorar a condição humana. De alguma forma, 
o conceito expressa a descrença na capacidade dos indivíduos em resolver os problemas que se apresentam.

O neoliberalismo contemporâneo, apregoado como a tábua da salvação do mundo, difere de seu antecessor por apostar sua força na ideia de libertação do indivíduo. Aparenta pressupor uma condição não cultural (pré-moderna) na constituição do mundo social. Decerto, isso parece mais querer consagrar o que existe como privação da liberdade, como forma de destino inexorável. É claro que o sentido civilizacional embutido na ideia de educação, com esta onda antimoderna, mina e fragiliza qualquer sentido democrático, cultural, plural e cosmopolita que outrora fora idealizado pelos pensadores e legisladores modernos.

Esse último aspecto pode ser considerado um dos pontos que merece atenção se desdobrarmos e analisarmos as implicações das narrativas de retrotopia que são assumidas na arena pública contemporânea. A pergunta feita por Michael Apple (2017) - A educação pode mudar a sociedade? estaria sendo respondida se nos valêssemos desta obra de Bauman de forma positiva, mas no sentido inverso à intenção de Apple. Vamos para o futuro numa onda de regresso, imaginando um passado nostálgico, perfeito e estável, o qual não representa uma ampliação das forças democráticas capazes de enfrentar as desordens sociais e excludentes do presente social contemporâneo, mas, puramente, uma forma de colocar ordem pela via da força das armas e da violência em detrimento da reflexão, do pensamento, do argumento, da educação e da cultura do diálogo.

Todo esse sentimento regressivo tem sido propagandeado e vendido para cada indivíduo de forma isolada, que o incorpora e o assume como valor e o difunde socialmente; um modo de educação que se desenvolve no cotidiano com a força do pensamento único, criando uma cultura e estabelecendo os comportamentos, atitudes e compreensões que, de alguma forma, determinam os rumos da humanidade. Como escreve Bauman (2017, p. 140), "nós somos pressionados a nos conformar e nós desejamos ser pressionados" porque "sermos guiados acaba com os medos de nos perdermos. A familiaridade consola e tranquiliza - ou, antes, nos mantém a uma distância segura de situações que peçam consolo e tranquilidade".

Nessa perspectiva teórica, também escreve Judith Butler (2017) em A vida psíquica do poder: teorias da sujeição. Tanto em Bauman quanto em Butler, o indivíduo/o sujeito precisa agir, reagir, tomar atitude. $\mathrm{Na}$ situação de domínio, de controle sistêmico da atualidade, contudo, o indivíduo bloqueia percepções, ações e reações e impede a segurança e, também, a liberdade, especialmente porque "a liberdade é valiosa quando ela e o potencial humano que ela supostamente viabiliza são reais" (BAUMAN, 2017, p. 108). As definições, as regras, que pautam o presente, são tarefas do presente, embora com perspectivas históricas, e, nesse aspecto, a memória é, também, central, por colocar os indivíduos do mundo, que hoje é compartilhado diante da objetividade da história e das circunstâncias constitutivas dos tempos vindouros, não como distantes e estranhos, mas como desenhos e tessituras do hoje.

Em Retrotopia, Bauman (2017) parece sugerir uma educação para a pesquisa permanente que contribua para ampliar a compreensão acerca das manifestações, dos fenômenos e tendências socioculturais e sistêmicas a partir de uma racionalidade concreta, de repercussões coletivas e mudanças de atitudes como que alertas para a responsabilidade individual e coletiva com a vida. Lendo a obra, lembramo-nos do livro de Eduardo Galeano (2001), De pernas pro ar: a escola do mundo ao avesso, e passamos a compreender como o mundo contemporâneo líquido-moderno (des)educa, o que significa valorar e agir em sentido inverso na educação formal/escolar/universitária, buscando construir outro significado sobre a arte de educar, no qual esteja claro o compromisso humano com o futuro do mundo, da democracia e da humanidade. Nesse tipo de visão, há tanto valor para o problema da crítica social quanto para o entendimento acerca do significado do pensamento, da reflexão, do conhecimento, da política, da ética, da convivialidade e da integração.

Pensar e conceber o lugar da educação na perspectiva baumaniana, a partir da obra Retrotopia (2017), significa movimentar-se em direção a uma cultura reflexiva e de diálogo, o que pode favorecer enormemente a construção de outras formas de lutar pelo valor da emancipação, da igualdade, da sustentabilidade, da solidariedade e da diferença. A educação é o caminho auxiliar para o humano colocarse de forma reflexiva e solidária no mundo, relacionando-se e reconhecendo as contingências e incertezas. O protagonismo dessa racionalidade aponta para o enfrentamento do tempo presente com novas 
posturas, compreensões e narrativas que considerem a historicidade, mas o façam de modo crítico, para que a história não se repita como farsa, o que pode nos permitir um enfrentamento das novas formas de dominação cultural emergentes no cenário líquido moderno.

\section{REFERÊNCIAS}

APPLE, Michael W. A educação pode mudar a sociedade? Petrópolis, RJ: Vozes, 2017.

BAUMAN, ZIGMUNT. Globalização: as consequências humanas. Rio de Janeiro: Jorge Zahar, 1999.

BAUMAN, Zygmunt. O mal-estar da pós-modernidade. Rio de Janeiro: Ed. Jorge Zahar, 1998.

BAUMAN, Zygmunt. A utopia possível na sociedade líquida. In: OLIVEIRA, Dennis. Entrevista Zygmunt Bauman. Revista Cult, n. 138, ano 12, 2009a.

BAUMAN, Zygmunt. Vida líquida. 2. ed. Rio de Janeiro: Ed. Jorge Zahar, 2009b.

BAUMAN, Zygmunt. Legisladores e intérpretes: sobre modernidade, pós-modernidade e intelectuais. Rio de Janeiro: Ed. Jorge Zahar, 2010.

BAUMAN, Zygmunt. Bauman sobre Bauman: diálogos com Keith Tester. Rio de Janeiro: Ed. Jorge Zahar, 2011.

BAUMAN, Zygmunt. Retrotopia. Rio de Janeiro: Zahar, 2017.

BUTLER, Judith. A vida psíquica do poder: teorias da sujeição. Belo Horizonte: Autêntica, 2017.

ECO, Umberto. Pape Satàn Aleppe: crônicas de uma sociedade líquida. 1. ed. Rio de Janeiro: Record, 2017.

FOUCAULT, Michel. Microfísica do poder. 16. ed. Rio de Janeiro: Edições Graal, 2001.

FREIRE, Paulo. Pedagogia da autonomia. São Paulo: Paz e Terra, 1996.

GALEANO, Eduardo. De pernas pro ar: a escola do mundo ao avesso. Porto Alegre: L\&PM, 2001.

HELLER, Ágnes; FEHÉR, Ferenc. El péndulo de la modernidad: una lectura de la era moderna después de la caída del comunismo. 1. ed. Barcelona: Ediciones Península, 1994.

JACOBY, Russell. O fim da utopia: política e cultura na era da apatia. Tradução Clóvis Marques. Rio de Janeiro: Record, 2001.

JACOBY, Russel. Imagem imperfeita: pensamento utópico para uma época antiutópica. Rio de Janeiro: Civilização Brasileira, 2007.

VATTIMO, Gianni. "Bauman só podia estar de acordo com um papa como Francisco". Entrevista com Gianni Vattimo. Revista IHU, jan. 2017. Disponível em: <http://www.ihu.unisinos.br/186noticias/noticias-2017/563850-bauman-so-podia-estar-de-acordo-com-um-papa-como-franciscoentrevista-com-com-gianni-vattimo>. Acesso em 20 de julho de 2020. 